Bolr. zool., liriv. S. Pauio g:125-811, 1985

\title{
SOBRE $O$ CRESCIMENTO RELATIVO DE CALLICHIRUS MAJOR (SAY, 1818) (CRUSTACEA, DECAPODA, THALASSINIDEA)
}

\author{
SERGIO DE ALMEIDA RODRIGUES \\ Departamento de Zoologia, Instituto de \\ Biociências, Universidade de São Pau- \\ 10. Endereço atual: Depto Ecologia Ge- \\ ral, Inst. Bioc. USP. Caixa Postal \\ 11461. Brasil. (recebido em 15.IV.1985)
}

RESUMO - 0 crescimento relativo do própodo dos primeiros pereiópodos de machos e fêmeas de Callichirus major foi estuda do em função do comprimento da carapaça. No quelipodo menor - crescimento é aproximadamente isometrico e semelhante nos dois sexos. No quelípodo maior o crescimento é alométrico ne gativo e semelhante nos dois sexos apenas durante a fase prê -puberal. Na fase puberal as fémeas continuam apresentando alometria negativa enquanto que nos machos a alometria torna -se acentuadamente positiva. Alëm disso, os machos apresen tam dois tipos de quelípodos com morfologia e padrão de cres cimento alométrico positivo distintos

ABSTRACT - Relative growth of the chelar propodi in male and female Callichirus major was investigated as a function of carapace lenght. The smaller chela exhibits a constant pat tern of near isometric growth in both sexes In the larger, growth is negatively allometrical and similar in both sexes during the pre-pubertal phase, but is markerly different in the pubertal phase, in which, females present a single pat tern of negative allometry and males a dimorphic pattern of positive allometry.

\section{INTRODUÇÃO}

Fala-se em crescimento relativo quando determinadas di mensōes aumentam segundo taxas iguais (isométricas) ou diferentes (alométricas) em relação a outras, levando, na segunda hipótese, a modificaçōes nas proporçōes ao longo do tem po.

A partir de trabalhos pioneiros como os de

Huxley (1932), Teissier (1935) e Huxley \& Teissier (1936), numero sos pesquisadores - como ressaltam Newcombe (1948), Teissier (1960) e Hartnoll (1978; 1982) - têm demonstrado que a relação entre o crescimento de uma parte do corpo ou de um órgão em relação ao todo pode ser satisfatoriamente descrita pela 
equação $y=b x^{\alpha}$, onde $y$ é a dimensão variāvel, $x$ a dimensão de referência e a e b são constantes, a geralmente denominada "constante de equilíbrio" e b "índice de origem" (Huxley \& Teissier, 1936)

Expressa logaritmicamente, a equação torna-se: $\log$ y = $\log b+a \log x$. Desta forma, quando o logaritmo dos valores de y è projetado contra os de $x$ obtém-se uma reta onde a expressa $a$ inclinação $e \mathrm{~b} o$ ponto de intersecção com 0 eixo dos y. Esta transformação logarítmica é considerada o método mais simples e claro para a exposição de dados referentes a crescimento relativo (Hartnoll, 1978; 1982)

Devido principalmente ao tegumento rígido, que permite medidas acuradas, e ao fenómeno da muda, que proporciona a subdivisão da ontogènese em fases bem definidas, os crustá ceos, particularmente os Brachyura, têm sido muito usados em investigações sobre o tipo de crescimento (Hartnoll, 1978)

No que diz respeito aos Thalassinidea, são poucas as contribuiçōes neste campo. Hailstone e Stephenson (1961) investigaram relaçōes entre o comprimento do corpo e da carapa ça e a largura do quelipodo maior em Callianassa australien= sis; Buchanan ( 1963 ) estudou a relação entre o comprimento da carapaça e o comprimento do corpo em Calocaris macandreae; e Devine (1966) relacionou o comprimento do corpo com a largura do quelípodo maior em Callianassa filholi.

No presente trabalho serão investigadas as relações en tre o comprimento da carapaça e o comprimento do própodo dos quelípodos de machos e fêmeas de Callichirus major $1818)$.

Os resultados aqui descritos foram apresentados ao Ins tituto de Biociências da Universidade de Sao Paulo como parte de uma Tese para a obtenção do tîtulo de Livre Docente (Rodrigues, 1983) e um resumo dos mesmos encontra-se jă pu blicado (Rodrigues, 1984).

\section{MATER IAL}

Cal-lichirus major foi originalmente descrito por Say (1818) como Callianassa major. Recentemente, Saint Laurent (1973) desdobrou o vasto gênero Callianassa em diversos gêne ros e designou $C$. major como espécie tipo do gênero Callichî rus, criado por Stimpson no século passado (stimpson,1866), mas considerado apenas como sub-gênero nas revisoes clás sicas do inficio do século (Borradaille, 1903; De Man, 1928b)

Embora considerado por Say (op. cit) um animal comum, a captura de $C$. major constituiu, durante longo tempo, um sê rio desafio aos carcinologistas.

Hay \& Shore (1918), trabalhando cem anos apös o achado original, concluiram que " the species is certainly one of the greatest rarity, for, in spite of the energetic work of many collectors through many years, only one specimen has been found". De Man (1928a), reunindo subsIdios para sua grande monografia $(1928 \mathrm{~b})$, conseguiu apenas dois quelipodos, depositados no Museu Británico, e uma fotografia do exemplar de Hay e Shore. Logo a seguir, uma excursão organizada pela 
Smithsonian Institution com o intuito de redescobrir $C$ ma jor não obteve sucesso (Schmitt \& Shoemaker, 1929).

Lunz (1937), na Carolina do Sul, desenvolveu a primeira técnica para a captura de $C$ major, obtendo cerca de 25 exemplares, porém sua descrição não fugiu aos padrões clās sicos da época, inadequados, segundo Gurney (1944)

A espécie foi assinalada no Brasil por Rodrigues(1965) e detalhadamente redescrita (Rodrigues, 1966; 1971) com base principalmente em exemplares procedentes de Santos. 0 materi al presentemente examinado, cobrindo uma ärea muito mais ampla, foi comparado com exemplares da Carolina do Norte. Dife renças foram observadas apenas nos dedos do quelipodo maior do macho (Figs. 1-30), onde o dátilo dos exemplares brasilei ros mostra um dente sub-terminal, ausente no exemplar procedente da Carolina do Norte (Fig. 13 ), bem como nas únicas ilustrações existentes (De Man, 1928a; Lunz, 1937). Por ou tro lado, o exemplar (Fig. 13) e ilustraçöes de material nor te americano mostram um dente bicúspide, robusto, junto à "ar ticulação; este dente às vezes se apresenta assim caracterizado nos exemplares brasileiros ( $F$ igs. $10,17,23,28$ ), mas uma grande variabilidade pode ser observada, principalmente levando-se em conta o' tamanho dos animais. No que diz respei to às fêmeas, a única diferença observada è a presença de um dente pontiagudo, às vezes biffido, na base do dedo fixo do quelipodo maior dos exemplares de Beaufort, como já registra do por Lunz (1937). Este dente näo foi observado no materiaI brasileiro.

Estas diferenças, no entender de alguns carcinologis tas, poderiam ser suficientes para justificar a criação de subespécies ou até mesmo de novas espécies. Neste trabalho, o taxon $C$ major foi aplicado a todo o material do Atlânticó americano pelas seguintes razões: do ponto de vista morfológico o material norte-americano encontra-se insuficientemente caracterizado, não sendo possivel excluir a hipótese de a presentar as variações observadas no material brasileiro; $e^{-}$ xiste uma grande lacuna na distribuição da espécie (entre o Maranhão e o Golfo do México), que pode refletir a falta de coletas ao longo desse litoral, onde a espécie pode estar presente e exibir gradações morfológicas de recobrimento entre as amostras das localidades jă pesquisadas

Foram analisados 259 exemplares - 132 machos e 127 fêmeas = coletados principalmente na Baía de Santos em 1978 , incluídos também exemplares coletados em diversos locais ao longo do litoral brasileiro, desde o estado de Sergipe até Santa Catarina, bem como um exemplar da Carolina do Norte.vá rias tentativas foram feitas para separar, biometricamente os exemplares por localidades, sem sucesso. Dos exemplares machos medidos, 4 näo foram incluídos na anălise grăfica por se encontrarem com o exoesqueleto mole, em virtude de recente ecdise, o que prejudica a precisão das medidas, ou por apresentarem quelipodos anormalmente pequenos em relação ao comprimento da carapaça, evidência de autotomia recente, seguida de regeneração.

A maioria dos exemplares estudados encontra-se depositada no Museu de Zoologia da Universidade de São Paulo, sob os números 5537 a 5843 


\section{METODOS}

Os animais foram capturados com uma bomba aspirante simples (Hailstone \& Stephenson, 1961; Rodrigues, 1966).

As medidas foram feitas com um paquimetro calibrado em décimos de milimetros. 0 comprimento da carapaça foi medido do ápice do rostro atê o ponto mediano da margem posterior. 0 comprimento do própodo dos quelípodos maior e menor foi me dido entre os pontos extremos da margem superior.

Os valores obtidos foram projetados em coordenadas 1ogaritmicas e a dispersão dos pontos empíricos analisada vi sualmente. A seguir, os dados brutos foram transformados em logarítmos e assim calculadas as equaçōes das retas que me lhor descrevem as relaçōes encontradas, utilizando-se o méto do dos minimos quadrados, conforme apresentado por Stanley (1963). Calculou-se tambêm o coeficiente de correlação linear de Pearson.

As tabelas de valores críticos utilizadas nos julgamen tos de significāncia $(\alpha=0,05)$ foram as apresentadas por $\mathrm{Za} \bar{r}$ (1974).

Os desenhos da morfologia dos dedos foram confeccionados com o auxilio de uma lupa binocular Wild M-5 munida de câmara clara.

\section{RESULTADOS}

A relaçāo entre o comprimento da carapaça $(x)$ e o comprimento do própodo do quelípodo menor $(y)$ de 110 fémeas encontra-se projetada no gráfico da Figura 31 . 0 segmento de reta foi traçado com auxilio da equação abaixo, cujo coefici ente de correlação $(r)$ foi altamente significante e, portanto, expressa adequadamente a relação investigada:

$$
\begin{aligned}
& \text { log } y=0,80 \log x-0,40 \quad(1) \\
& \text { sendo } r=0,895
\end{aligned}
$$

O padrão de dispersão dos pontos e a equação (1) constituem uma indicação de que a proporção entre o comprimento da carapaça e do própodo do quelipodo menor modifica-se segundo a mesma taxa. A inclinação da reta $(\alpha<1)$ caracteriza uma alometria do tipo minorante.

$\mathrm{Na}$ Fig. 32 encontra-se expressa a relaçāo entre o comprimento da carapaça $(x)$ e o comprimento do própodo do quelí podo menor $(y)$ de 118 machos. A equação da reta que caracteriza a relaçao entre estas duas medidas (cujo coeficiente de correlação tambèm se mostrou altamente significante) è a seguinte:

$$
\begin{aligned}
& \text { log } y=0,95 \log x-0,56 \\
& \text { sendo } r=0,850
\end{aligned}
$$

Tanto a anâlise visual como a equação obtida indicam que, durante a vida dos machos, dentro dos intervalos de com primento analisados, a proporçáo entre o comprimento do prōpodo do quelípodo menor em relação ao comprimento da carapa ça permanece praticamente constante. A inclinaçāo da reta $\left(43,53^{\circ}\right)$ mostra que este pereiópodo apresenta um crescimento 
que se aproxima ao do tipo isométrico.

Comparando as Figs. 31 e 32 , bem como as equaçōes (1) e (2), observa-se que o crescimento do quelípodo menor é basicamente semelhante em ambos os sexos. Nos machos, como indica a inclinação da reta, este crescimento parece ser um pouco mais acentuado.

A Fig. 33 apresenta a relação entre o comprimento da carapaça ( $x$ ) e do própodo do guelípodo maior (y) de 125 fè meas. Nota-se que os pontos nảo se distribuem uniformemente, havendo uma descontinuidade no eixo do comprimento da carapa ça no intervalo $11-14 \mathrm{~mm}$. Nesta faixa, para um mesmo compri= mento de carapaça, observa-se a presença de exemplares com própodo curto $(e . g .4 \mathrm{~mm})$, bem como com este artî́culo mais longo $(e . g .6 \mathrm{~mm})$. Observa-se ainda que todas as fêmeas ovígeras, representadas no gráfico por círculos vazios, encon tram-se agrupadas na nuvem superior, numa faixa de comprimen to de carapaça logo acima da zona de descontinuidade.

Estas evidências constituem uma indicação de que os exemplares com o comprimento de carapaça entre 11 e $14 \mathrm{~mm}$ sofrem o que costuma ser denominado muda critica, envolvendo alteração no padrão de crescimento do quelípodo maior, tipicamente associada com importantes modificaçoes no funciona mento do sistema endócrino, relacionadas com a maturação se xual e separando duas fases do crescimento, tradicionalmente denominadas pré-puberal e puberal (Teissier, 1960)

Tratando separadamente as coordenadas acima e abaixo da faixa de descontinuidade, foram obtidas duas equaçōes relacionando o comprimento da carapaça $(x)$ e o comprimento do própodo $(y)$ do quelípodo maior de 79 fêmeas na fase puberal e 46 na fase prê-puberal.

reta superior: $\log y=0,90 \log x-0,28$

(fase puberal) sendo $r=0,787$

reta inferior: $\log y=0,76 \log x-0,22$

(fase pré-puberal) sendo $r=0,821$

A anālise grâfica da Fig. 33 e as equaçōes (3) e (4) sugerem que o crescimento do quelípodo maior das fêmeas apre senta alometria minorante, com duas fases distintas, caract $\overline{\underline{e}}$ rizadas por duas retas paralelas, com elevaçōes diferentes.

A Fig. 34 mostra a relação entre o comprimento da cara paça $(x)$ e o comprimento do própodo $(y)$ do quelípodo maior de 128 machos. Como no caso do quelípodo maior das fêmeas, e xiste também aqui uma descontinuidade no eixo do comprimento da carapaça no intervalo $11-14 \mathrm{~mm}$.

Tratando as coordenadas abaixo da descontinuidade de maneira semelhante à descrita para o quelipodo maior das fêmeas, resulta uma equação que expressa o crescimento do própodo do quelípodo maior em relaçao ao comprimento da carapaça de 27 machos durante a fase pré-puberal.

$$
\begin{aligned}
& \log y=0,64 \log x-0,13 \quad \text { (5) } \\
& \text { sendo } r=0,606
\end{aligned}
$$

Comparando (4) e (5), constata-se que durante a fase pré-puberal, o quelípodo maior, tanto dos machos como das fế meas, apresenta um crescimento básico semelhante, caracterizado por uma alometria do tipo minorante $\left(\alpha^{<} 1\right)$ 
Considerando agora a fase puberal dos machos,correspondente aos valores acima da faixa de descontinuidade, ou seja, onde o comprimento do própodo é maior que 4,7 $\mathrm{mm}$, uma comparação com o resultado obtido para as fêmeas torna -se mais dificil, pois a nuvem de pontos representa machos com quelipodo maior de dois tipos. Um, representado na Fig. 34 por circulos cheios e a partir de agora denominado macho puberal, é basicamente igual ao da fase pré-puberal e pode ser apreciado nas Figs 1 a $4,16,19$ a 21 . Outro, representado na Fig. 34 por círculos vazios e denominado agora macho típico, é nitidamente diferente do anterior, principalmente no que diz respeito aos dedos, como pode ser visto nas Figs 5 a $15,17,18,20,22$ a 30 . Alểm da forma, também a ação dos dedos é diferente, pois o dátilo do primeiro tipo, ao fe char-se sobre o dedo fixo, fica voltado para dentro, enquan= to que os do segundo tipo se voltam para fora.

Calculando uma reta para cada tipo, obtểm-se duas equa ções que expressam o crescimento do quel ipodo maior de 29 mâ chos puberais e 72 tipicos em relação ao comprimento da carā paça.

machos puberais:

$$
\log y=1,38 \log x-0,72
$$

$$
\begin{aligned}
& \text { sendo } r=0,904 \\
& \log y=1,25 \log x-0,44
\end{aligned}
$$

machos tipicos:

$$
\text { sendo } r=0,678
$$

0 padrão de dispersão dos pontos da Fig. 34 e as equaçōes (5), (6) e (7) sugerem que o própodo do quelípodo maior dos machos apresenta, na fase pré-puberal, um crescimento ti po alométrico minorante, que se modifica, após a fase de muda critica, para alométrico distintamente majorante $(\alpha>1)$, caracterizado por duas retas paralelas, porém com elevaçōes distintas, correspondentes aos dois tipos morfológicos jă de nominados puberal e tipico.

\section{DISCUSSĀO}

Hailstone e Stephenson (1961), em seus estudos com Cal lianassa australiensis, concluiram que inicialmente o crescí mento do quelípodo maior em relação ao da carapaça è seme Ihante nos dois sexos, modificando-se em seguida de modo que nos machos o quelípodo cresce proporcionalmente mais rápido do que a carapaça, ao passo que, nas fêmeas, o crescimento do quelipodo e proporcionalmente mais lento do que o da cara paça. Afirmaram também que o crescimento tanto do comprimento do quelipodo maior como o da carapaça, em relação ao comprimento do corpo, estava "longe de ser simples".

No que diz respeito ao crescimento do quelípodo em relação ao da carapaça, os resultados se assemelham aos obti dos para $C$ mafor. Quanto às comparaçōes com o comprimento do corpo, a utilização desta medida como dimensão de referên cia pode contribuir para aumentar o erro das medidas, pois $\frac{1}{0}$ 
abdome, composto por seis metâmeros separados por membranas inter-articulares, está mais sujeito a variações devido a contração ou distenção. Acrescente-se o fato de que os dados não sofreram a transformação logarîtmica recomendada (Teissier, Hartnoll, op. cit), o que obscurece as interpretações e dificulta comparações. o mesmo pode ser dito com relação aos dados de Devine (1966) que, constatando pouca ou nenhuma diferença na proporção entre o comprimento do corpo e o da carapaça, utilizou o primeiro como dimensão de referência pa ra investigar as diferenças de crescimento do quelipodo mai= or em machos e fèmeas, concluindo que o padräo era semelhante ao descrito para $C$. australiensis por Hailstone e Ste phensen (op. cit).

Dentre os braquiuros, um exemplo clássico e considerado típico (Hartnoll, 1978) è o do crescimento relativo de Maia squinado (Teissier, 1935), onde o comprimento do própodo em relação ao da carápaça prestou-se para caracterizar três fases de crescimento pós-larval: juvenil, pré-puberal e puberal. A transição entre a fase juvenil e a pré-puberal não envolve modificaçōes morfológicas reconhecíveis em indivíduos isolados, mas aparece como uma inflexão na curva de crescimento. A transiçăo entre a fase pré-puberal e a pube ral é marcada por uma nitida descontinuidade que corresponde a muda puberal.

Os resultados obtidos para $C$. major (Figs. 31-34) não permitem caracterizar a fase juvenil. Enquanto não forem conseguidos exemplares onde o comprimento da carapaça seja inferior a $5 \mathrm{~mm}$, nada se pode conjecturar sobre as constan tes que caracterizam esta fase. Por outro lado, a transiçāo entre a fase pré-puberal e a puberal é marcada, tanto nos ma chos como nas fêmeas, por nîtidas descontinuidades na curvā de crescimento, envolvendo mudanças nos indices de origem $e$ nas constantes de equilíbrio.

o polimorfismo apresentado pelos machos de $C$. major na última fase de crescimento pode ser considerado como uma ela boração do padrão tîpico, exemplificado por $M$. squinado, com parāvel ao descrito por Vernet-Cornubert (1958) para o bra = quiuro $P i s a$ tetraodon. A nitida separação entre os pontos re ferentes aos machos puberais e tipicos de $P$. tetraodon (Vernet-Cornubert, 1958 :fig. 7) contrasta com a superposiçāo observada em $C$. major, e explica-se pelo fato de que naquela familia de braquiuros não ocorrem mais mudas ao ser atingida a maturação sexual, a passo que os Thallassinidea continuam realizando ecdises durante a fase puberal.

Segundo Vernet-Cornubert (op.cit), o polimorfismo apresentado pelo quelipodo maior dos machos de $P$.tetraodon na ultima fase de crescimento sugere gue nāo existe um completo relacionamento entre a diferenciaçao dos caracteres sexuais secundârios e a maturação das gônadas. Assim sendo, a muda critica que marca a transição entre a fase pré-puberal e a puberal poderia acontecer em um momento onde os caracteres sexuais secundârios não atingiram seu aspecto final, resul tando em animais sexualmente maduros e funcionais com caracteres juvenis Analisando os quelipodos dos machos de $C$ mafor, sob este prisma, ressalta ainda mais que as diferenças 
entre as fases prê-puberal e puberal dizem respeito muito mais às dimensões do que à forma.

As diferentes formas sāo simpátricas e sintópicas, não havendo maiores motivos para suspeitar de que se tratem de taxons diferentes. A este respeito, cabe lembrar aqui a ob servação de Gould (1966): "Formas novas, produzidas pela pro gressão de uma relação alométrica em novas amplitudes de tamanho, não são critêrios taxonômicos independentes. (...) o não reconhecimento de consequências alométricas tem levado frequentemente à criação, sem fundamento, de taxons entre or ganismos que diferem apenas em um carăter, cujos efeitos com plexos não foram considerados"

AGRADECIMENTOS - AO Dr. Roger $J$ Lavallard por despertar minha atengão sobre o assunto, sugestões e leitura do texto. Ao Dr. Martin L. Christoffersen pelo material da Carolina do Norte. Aos ex-estagiários Claudia Marina Flo, Horácio Higushi, Rosane Lopez Teixeira Mendes e Sérgio Luiz de Siqueira Bueno, pela colaboração nas coletas e medicōes. Ao Sr. Rober to M. Shimizu pelos desenhos dos dedos e callculo das retas Ao CEBIMAR pela acolhida em suas dependências.

\section{REFERENCIAS}

BORRADAILE, L.A. 1903 On the classification of the Thalas sinidea. Ann.Mag. Nat. Bist., ser. 7, 12:534-51

BUCHANAN, J.B. 1963 The biology of Calocaris macandreas (Crustacea, Thalassinidea). J.mar.biol.As8.U.K., $13(3)$ : $729-47$

DEVINE, C.E. 1966. Ecology of Callianassa filholi Milne Edwards, 1878 (Crustacea, Thalassinidea). Trans, $R$ Soc. $N$. 2., $8(8): 93-110$.

GOULD, S.J. 1966. Allometry and size in ontogeny and phyloge ny. Biol.Rev., 11 (4):587-640.

GHRNEY, R. 1944. The systematics of the Crustacean Genus Cal lianasea. Proc.zool. Soc.Lond., 114(5):82-80.

HAILSTONE, T.S. \& STEPHENSON, W. 1961. The biology of Callia nassa (Trupaea) australiensis Dana, 1952 (Crustacea, Thalassinidea). Pap.Dep.Zool.Univ.Qd, 1 (12):259-85.

HARTNOLL, R.G. 1978. The determination of relative growth in crustacea. Crustaceana, 34(3):281-93.

HARTNOLL, R.G. 1982. Growth. In: BLISS, D.E. (ed.), The Biology of Crustacea. Embriology, Morphology and Genetics v. 2, p. 111-96, Academic Press, New York.

HAY, W.P. \& SHORE, C.A. 1918. The decapod crustaceans of Beaufort, N.C., and the surrounding region. Bull.Bur. Eish.s $35: 371-475$.

HUXLEY, J.S. 1932. Probleme of relative growth. 276 p., Me thuen, London.

HUXLEY, J.S. \& TEISSIER, G. 1936 . Terminologie et notation dans la descrition de la croissance relative. C.r.Acad. Sei., Parie, 121: 934-6.

LUNZ, G.R. 1937 . Notes on Callianassa major Say. Charleston Mus.Leafl., 10:1-16. 
MAN, J.G. de 1928a. A contribution to the knowledge of twenty-two species and three varieties of the genus Callianas sa Leach. Capita zool., 2(6):1-56.

MAN, J.G. de 1928 b. The Thalassinidea and Callianassidae col lected by the Siboga-Expedition with some remarks on the Laomediidae. In: SIBOGA-EXPEDITIE: The Decapoda of the Si boga Expedition. vol. 39 a part 7187 p., E.J.Brill, Lei= den.

NEWCOMBE, C.L. 1948. An application of the allometry equa tion to the study of growth in Callinectes sapidus Rath bun. Amer. Nat., 82:315-25.

RODRIGUES, S. de A. 1965. Ocorrēncia de Callianassa major Say no litoral de São Paulo. Ciênc.Cult., $17(2): 226$.

RODRIGUES, S. de A. 1966 Estudos sobre Cailianassa: sistemá tica, biologia e anatomia. São Paulo, Universidade de São Paulo. 168 p. Tese (Doutorado).

RODRIGUES, S. de A. 1971. Mud shrimps of the genus Callianas sa Leach from the brazilian coast (Crustacea: Decapoda) Archos.Zool.Est.S Paulo, 20 (3):191-223.

RODRIGUES, S. de A. 1983 Aspectos da Biologia de Thallassinidea do Atlântico Tropical Americano. Sáo Paulo, Universidade de São Paulo. 174 p. Tese (Livre Docência).

RODRIGUES, S. de A. 1984. Crescimento relativo de Calliani dea laevicauda Gill e Callichirus major (Say) (Crustacea, Thalassinidea) - Ciēnc.Cult., $36(7): 914$

SAINT LAURENT, M. de 1973 Sur la systématique et la phylogé nie des Thalassinidea: définition des familes des Callianassidae et des Upogebiidae et diagnose de cinq genres nouveaux (Crustacea, Decapoda). C.r.Acad.Sci., Pario, 277 $513-6$.

SAY, T 1818 An account of the Crustacea of the United States. J.Acad.nat.Sci.Philad., $1(2): 235-53$.

SCHMITT, W.L. \& SHOEMAKER, C.R. 1929. The Crustacea of Beaufort, North Carolina. In: EXPLORATIONS and Fieldwork of the Smithsonian Institution in 1928. p. 85-8, Washington.

STANLEY, J 1963 . The essence of biometry. 147 p., McGill Univ. Press, Montreal.

STIMPSON, W. 1866. Descriptions of new genera and species of macrurous Crustacea from the coasts of North America Proc.Chicago Acad.Sci., 1:46-8

TEISSIER, G. 1935 . Croissance des variants sexuels chez Maia squinado L. Trav. Sta. Biol.Roscoff, $13: 93-130$.

TEISSIER, G. I960. Relative growth. In: WATERMAN, T.H. (ed.)The physiology of Crustacea, V. 1 p. 537-560, Academic Press, New York.

VERNET-CORNUBERT, G. 1958 Biologie générale de Pisa tetraodon (Pennant): Bull. Inst.océanogr., $1113: 1-52$.

ZAR, J.H. I974. Biostatiscal Analysi:. 620 p., Prentice Hall, Englewood Cliffs. 
Figuras 1-15 - Callichirus major: dedos de quelipodo maior direito de machos, em ordem crescente de comprimento, lado externo. Fig. 13, exemplar da Carolina do Norte; demais figu ras, exemplares brasileiros. 

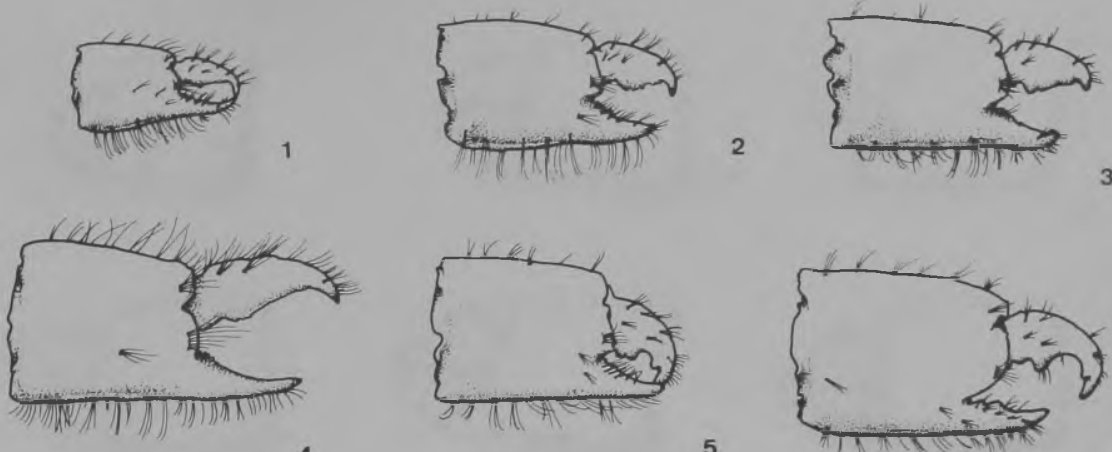

4

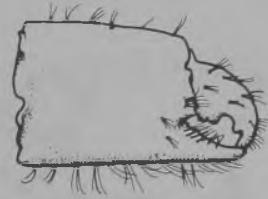

5
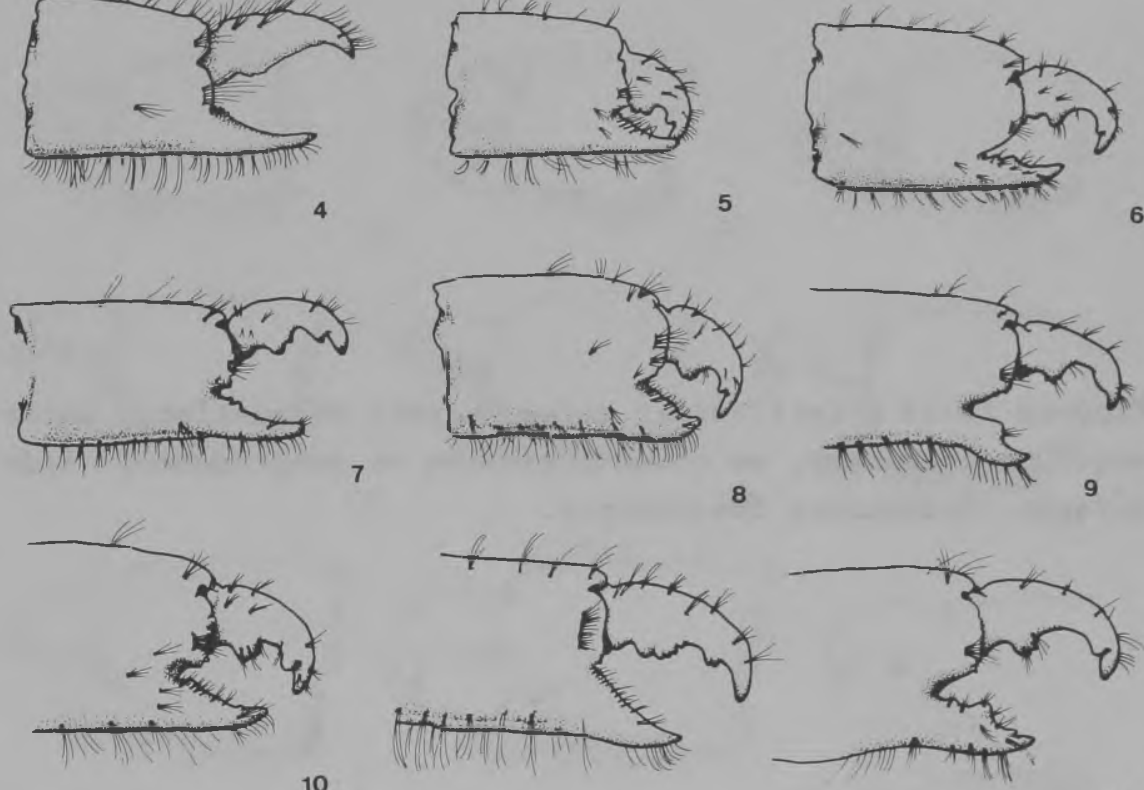

11
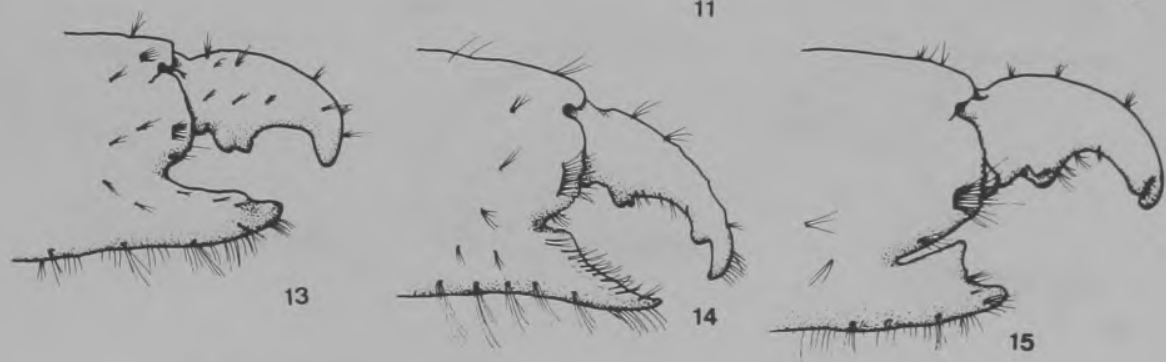
Figuras 16-30 - Callichirus major: dedos de quelípodo maior esquerdo de machos, em ordem crescente de comprimento, lado externo. Exemplares brasileiros. 


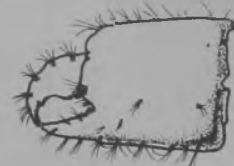

16
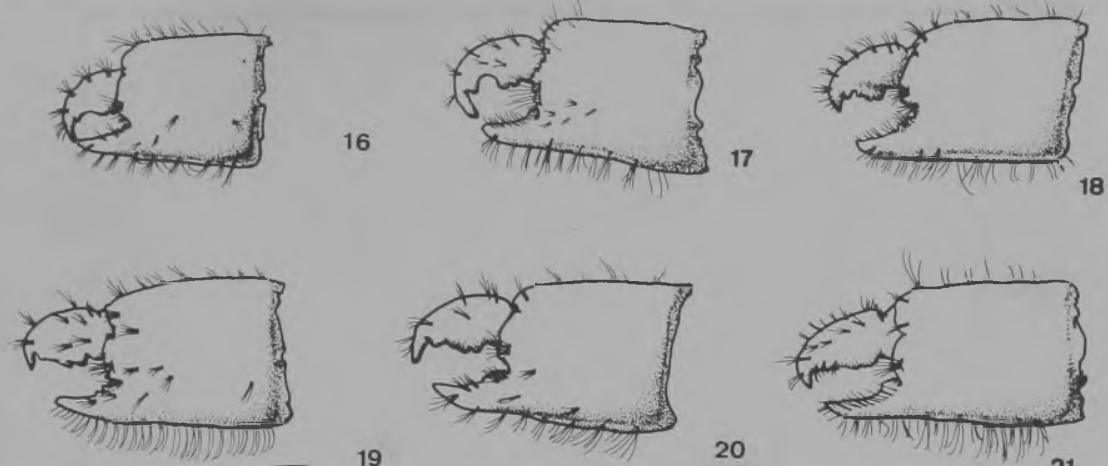

19

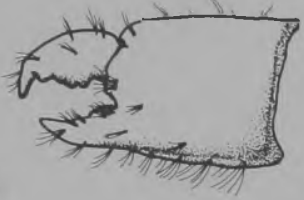

20
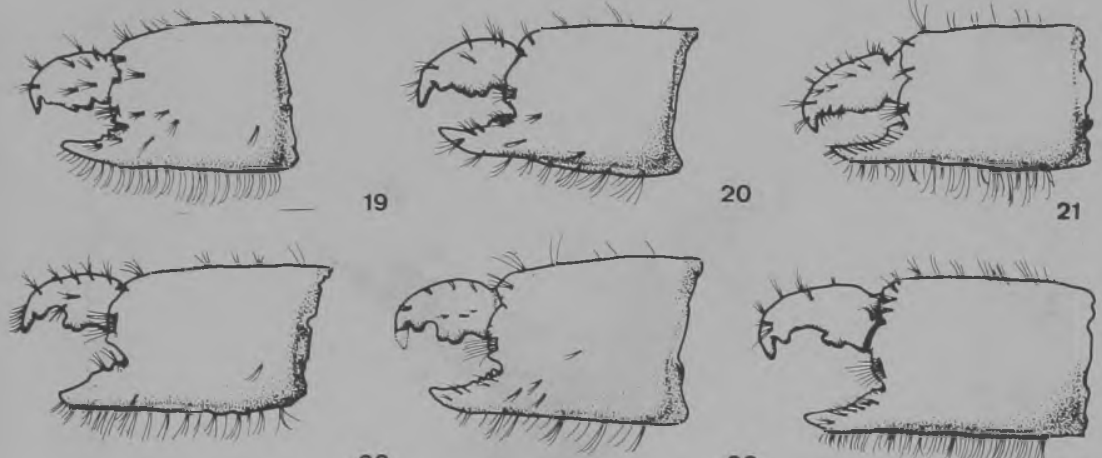

22

17

18

23
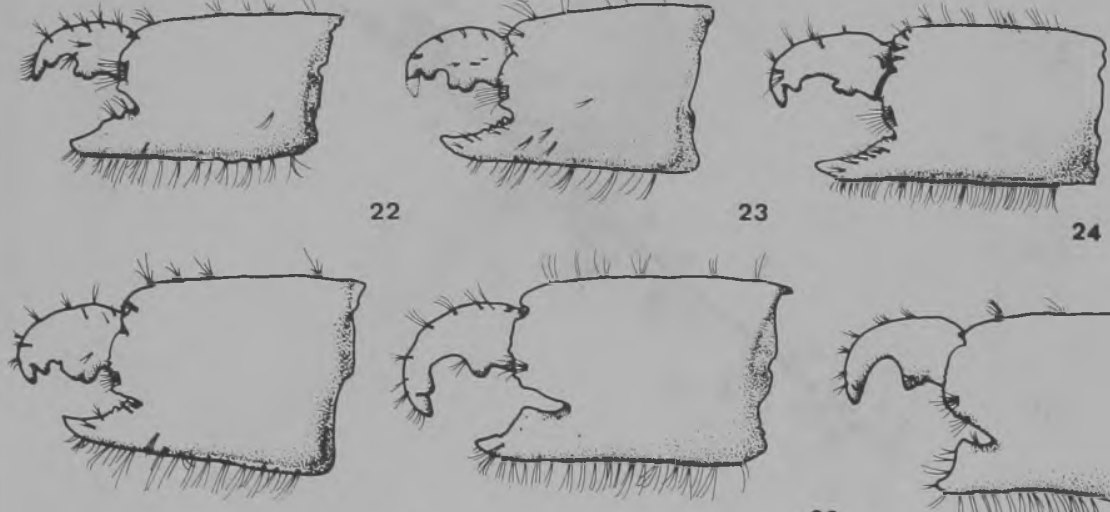

25
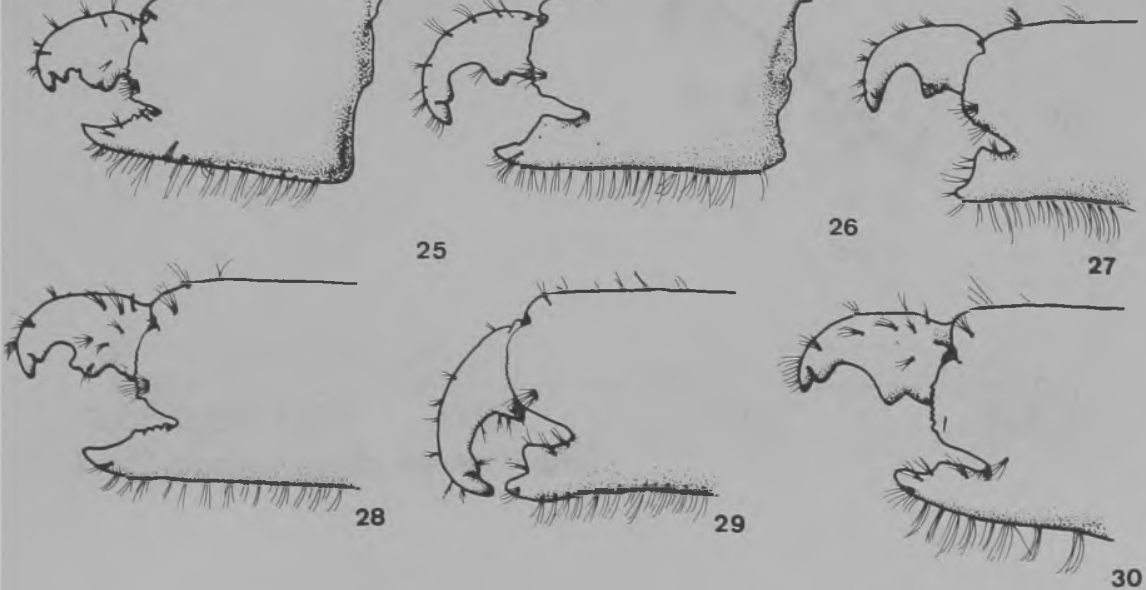


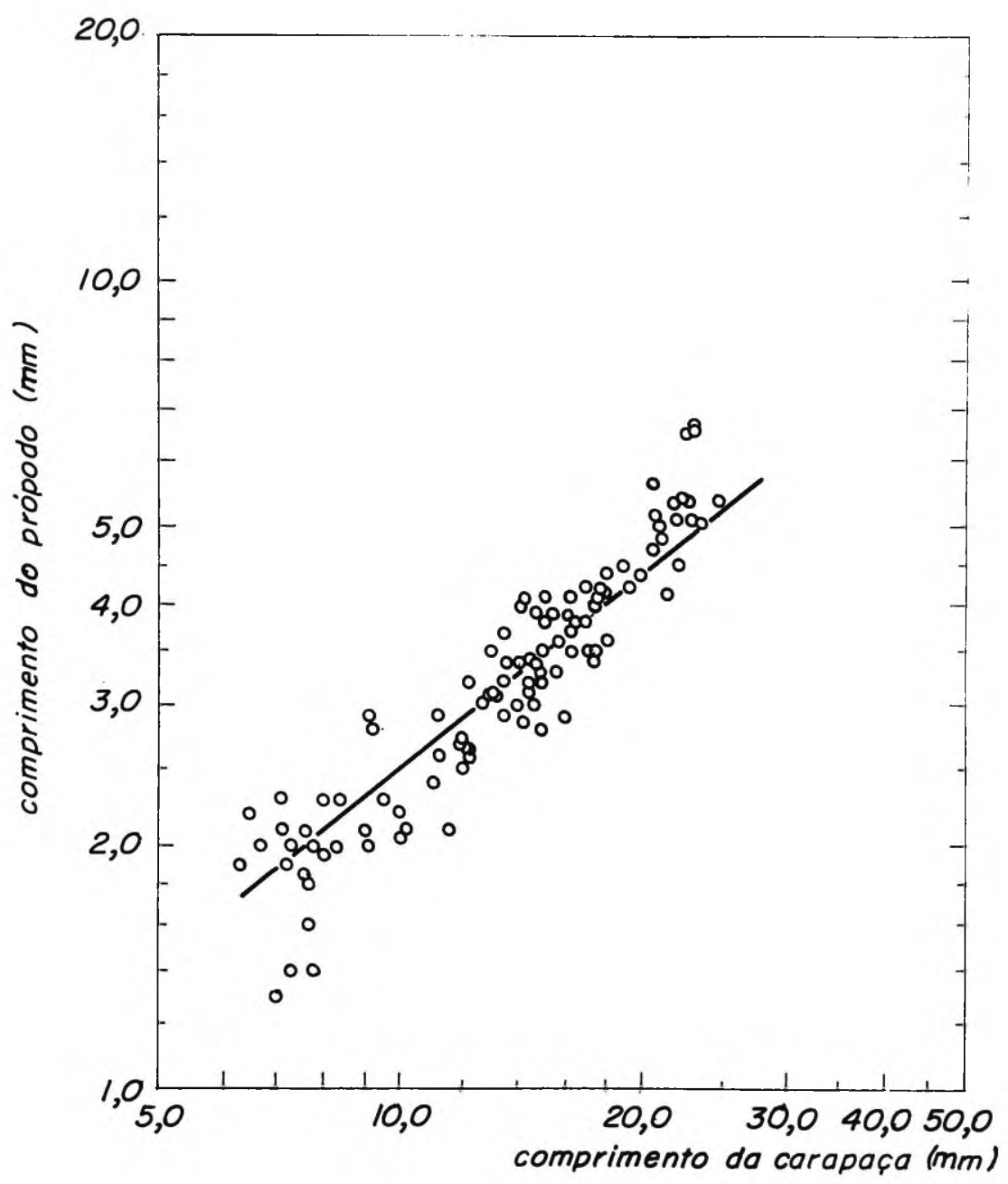

Figura 31 - Callichirus major: relação entre o comprimento da carapaça (mm) e o comprimento do própodo do quelïpodo menor (mm) em fêmeas. 


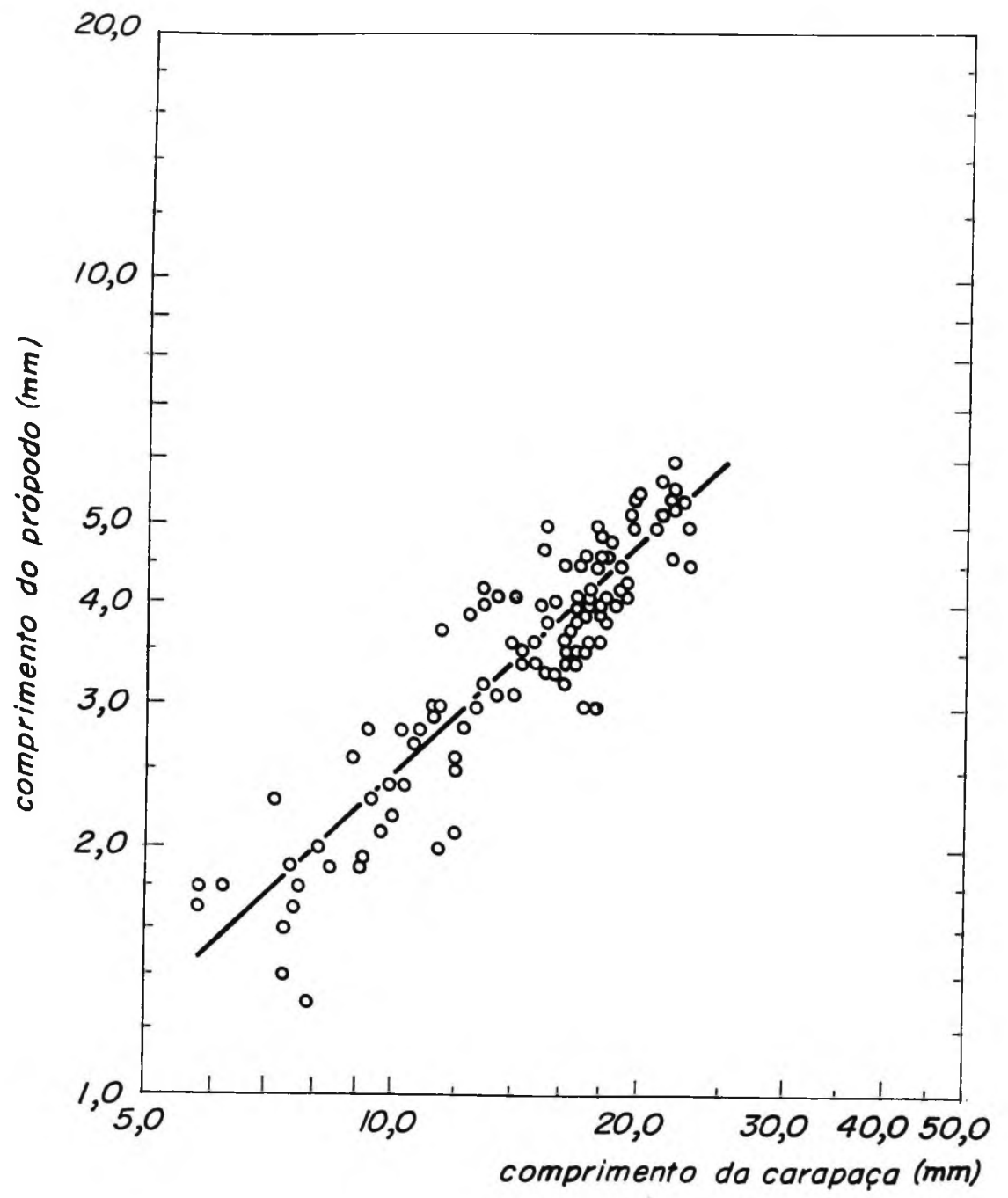

Figura 32 - Callichirus major: relação entre o comprimento da carapaça (mm) e o comprimento do própodo do quelípodo me- 


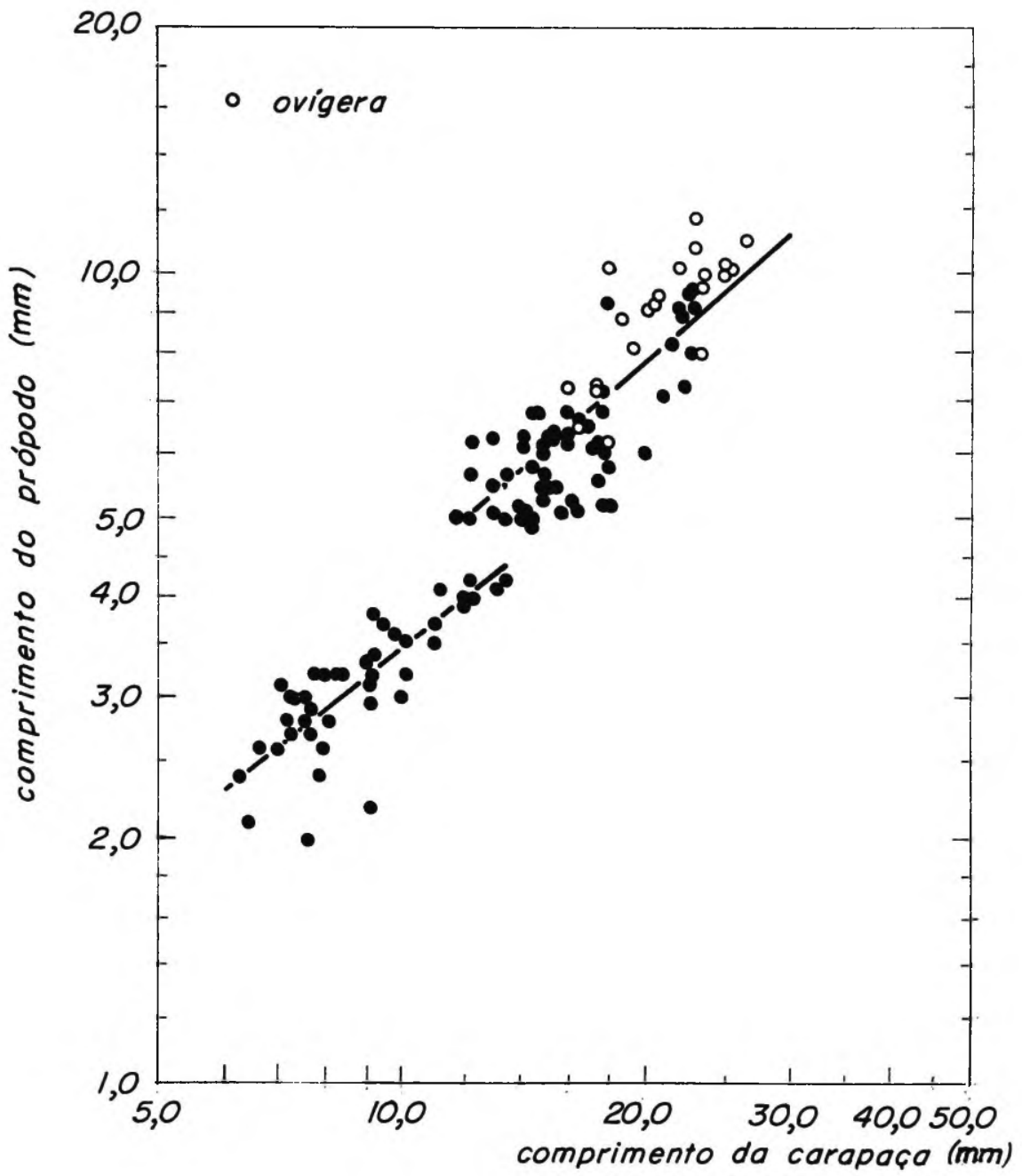

Figura 33 - Callichirus major: relação entre o comprimento da carapaça $(\mathrm{mm})$ e o comprimento do própodo do quel ípodo mai or (mm) em fêmeas. A reta superior representa a relação en fêmeas na fase puberal e a inferior, em fase prê-puberal. As fêmeas ovigeras estão apresentadas sob forma do circulos vazios. 


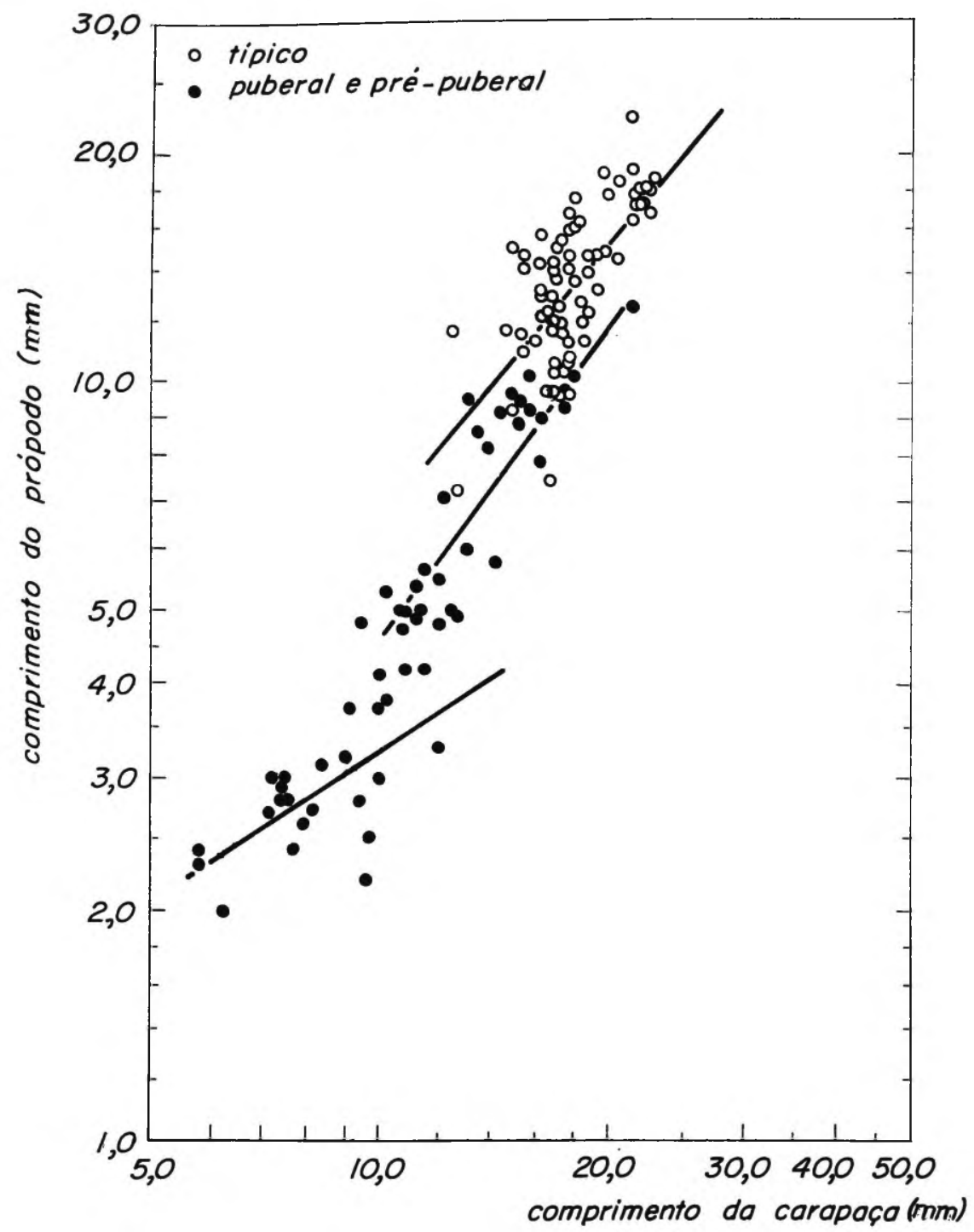

Figura 34 - Calliahirus major: relação entre o comprimento da carapaça ( $\mathrm{mn}$ ) e o comprimento do própodo do quelípodo maí or $(\mathrm{mm})$ em machos. A reta inferior representa a relação nos machos em fase pré-puberal e as retas mediana e superior, em fase puberal, com dois aspectos morfologicamente distintos os machos com o quelipodo de forma tipica estão apresentados sob forma de circulos vazios Para maiores detalhes, vide texto. 
